\title{
A child's guide to Soviet science
}

\section{The openness with which the Soviet Vega project was conducted at the weekend is both a pointer to the nature of Soviet science and a sign of how fruitful collaboration might be extended.}

\begin{abstract}
Moscow
WHAT can be learned about Soviet science in a mere five days in Moscow? Not much, of course. But the way in which the Vega project has been conducted in the past week, with quite astonishing frankness and friendliness, points to some important questions about the nature of the enterprise, and suggests some cheerful answers. The legend, in the West, that Soviet science is locked from sight of others behind a veil of paranoic secrecy is plainly, at best, a half truth.
\end{abstract}

The Vega project is the creation of one man, 54-year-old Academician R.Z. Sagdeev, who has been director of the Soviet academy's Institute of Space Sciences since 1973 . He is Russian in the energetic mould, small, wiry and with a wry tongue. Part of the way through an account last week of how his laboratory has been simulating the effects of dust particles on metal targets, he could not suppress a reference to "other people's" interest in accelerating particles to high velocities "for other purposes". Last November, Sagdeev was the only scientist among the party of Soviet advisers at the Geneva summit.

The origins of the Vega project are interesting in themselves. Several people claim part of the credit. The Vega launchings were originally scheduled chiefly as vehicles for a collaborative experiment with the French for the exploration of the atmosphere of Venus by means of balloons. In the event, it seems to have fallen to the then director of science at the European Space Agency (ESA), at a threehour meeting at Moscow airport, to persuade Sagdeev "to fly to Halley as well".

The project has been thoroughly international, with no trace of chauvinism. Collaborators from elsewhere have been invited on the basis that their instruments have a valuable contribution to make. J.A. Simpson, from the University of Chicago, for example, says that his instrument (which records dust particles penetrating an electrically anisotropic dielectric between two metal foils by means of the nanosecond voltage pulses they generate) is on board because a Soviet scientist heard him describe the instrument at a meeting; the invitation to Vega followed quickly, and was irresistible.

Other collaborators speak warmly of the informality of the collaboration. Dr Jochen Kissel from Heidelberg, whose dust detector is a mass spectrometer of novel design, says that Sagdeev's institute has been easier to deal with than the US Aeronautics and Space Administration (NASA) and even ESA, both of which require more paperwork. This is especially interesting because relations between the Soviet and West German governments do not officially exist (although there is an agreement on scientific collaboration between the Soviet academy and its West German counterpart, the Deutsche Forschungsgemeinschaft), which is why the collaboration has had to be laundered through France.

Kissel also says that the Soviets have been more daring than other agencies would have been in their willingness to fly instruments not previously used. This applies both to his present instrument and to that on which he is collaborating with Sagdeev's institute to produce a chemical analysis of the surface of the martian satellite Phobos by firing a powerful laser at the surface and collecting samples of the plasma thus generated, all this in the few minutes during which the instrument will be near the satellite, ideally a few metres up.

Not all Soviet institutes have this reputation for daring, of course. Part of the explanation at Sagdeev's institute is Sagdeev himself; his colleagues say that he has made a tremendous difference to the spirit of the place, especially by the recruitment of able scientists from elsewhere. (Even so, people say, there remains some of the dead wood that is the bane of the Soviet research system.) Another is the literal nature of the Soviet regard for the material world, of which science is a description; if there are good theoretical reasons for supposing that some phenomenon should occur, what reason can there be for behaving as if it will not? The Soviet educational system may also help; the way that the better university students spend two or three years at an institute before their first degree, often in the expectation of staying on, while frequently the reason for the accumulation of dead wood, can be in the hands of a daring director a way of finding firebrands.

Sagdeev's successful pursuit of international collaboration seems also to be an illustration of the independence that the director of a Soviet institute can enjoy. I have no means of knowing what the chauvinistic pressures may be, although the Soviet space programme has traditionally made a point of involving others through its "Interkosmos" programme.
So too has the US programme in its time. But the West is now mostly in the costsharing mode; collaborators pay their share of the overheads as well as their direct costs. Sagdeev has obviously been able to make the most of Soviet readiness to be flexible on these points. Other institute directors could no doubt follow suit if they were so inclined. It will be interesting to see if Sagdeev's example rubs off.

The other striking feature of the past week has been the frankness with which the details of the Vega project have been displayed. Visiting dignitaries were at first somewhat startled to find themselves expected to discuss where collaboration should go next (solar-terrestrial physics seems to be the favourite) in the presence of journalists. Most experimenters took well to the notion that they should provide virtually a kind of running commentary on their data.

The proceedings have been starkly in contrast with the way that even NASA handles these affairs. (The NASA official who said in public that "even we have something to learn" knew that he had blundered before the word "even" had escaped his lips.) But this is not the first time that the Soviets have startled the West by frankness. In 1958, for example, V.A. Kurchatov astounded a British audience at the Atomic Energy Research Establishment at Harwell with a full account of the Soviet thermonuclear programme, from which stemmed the stillcontinuing international collaboration in that field. Kurchatov was succeeded as director of the Soviet establishment at Dubna by the even more outspoken Artsimovich, himself a one-time colleague of Sagdeev.

It is far from fanciful to think this lineal connection between people who know the value of frankness is significant. Moreover, it is not necessary to suppose that there has been a high-level decision by the Soviet government that the scientific part of the space programme should be made "open". As the French have known for some time, it has always been more accessible than it may have seemed. On this occasion, Sagdeev's personal interest, and his success, seem to have been the mainsprings of what appears to have been a change (but which may be simply a mark of a neglected opportunity). This, obviously, is another example that other Soviet directors, and potential partners in the West, may follow.
John Maddox 